\title{
ZnO Nanoparticles-Chitosan Composite as Antibacterial Finish for Textiles
}

\author{
Asmaa Farouk, ${ }^{1,2}$ Shaaban Moussa, ${ }^{3}$ Mathias Ulbricht, ${ }^{4}$ and Torsten Textor ${ }^{1,5}$ \\ ${ }^{1}$ Deutsches Textilforschungszentrum Nord-West gGmbH (DTNW), 47798 Krefeld, Germany \\ ${ }^{2}$ National Research Centre, Textile Division, Textile Chemistry and Technology, Department of Preparation and Finishing of \\ Cellulosic Fibers, Tahrir Street, Dokki, P.O. Box 12622, Giza, Egypt \\ ${ }^{3}$ Genetic Engineering and Biotechnology Research Institute, Minoufiya University, P.O. Box 79/22857, El-Sadat City, Egypt \\ ${ }^{4}$ Universität Duisburg-Essen, Technical Chemistry II, Universitätsstrasse 7, 45141 Essen, Germany \\ ${ }^{5}$ Center for Nanointegration Duisburg-Essen CeNIDE, 47048 Duisburg, Germany \\ Correspondence should be addressed to Asmaa Farouk, asmaafarouk2003@yahoo.com
}

Received 24 September 2012; Revised 6 November 2012; Accepted 6 November 2012

Academic Editor: J. F. Vliegenthart

Copyright () 2012 Asmaa Farouk et al. This is an open access article distributed under the Creative Commons Attribution License, which permits unrestricted use, distribution, and reproduction in any medium, provided the original work is properly cited.

The antibacterial performance of sol-gel-derived inorganic-organic hybrid polymers filled with ZnO nanoparticles-chitosan against a gram-negative bacterium Escherichia coli and a gram-positive Micrococcus luteus has been investigated. Three different molecular weights (MW) of chitosan (CTS) $1.36 \cdot 10^{5}, 2.2 \cdot 10^{5}$, and $3.0 \cdot 10^{5} \mathrm{Da}$ with equal degree of deacetylation (DD, 85\%) (coded as S 85-60, He 85-250, and He 85-500) with equal degree of deacetylation (DD, 85\%) were examined. ZnO was prepared by the base hydrolysis of zinc acetate in isopropanol using lithium hydroxide $\left(\mathrm{LiOH} \cdot \mathrm{H}_{2} \mathrm{O}\right)$ to hydrolyze the precursor. Sol-gel-based inorganic-organic hybrid polymers were modified with these oxides and were applied to cellulosic cotton (100\%) and cotton/polyester (65/35\%) fabrics. Inorganic-organic hybrids polymers were based on 3-glycidyloxypropyltrimethoxysilane (GPTMS). Bacteriological tests were performed in nutrient agar media on solid agar plates and in liquid broth systems using $\mathrm{ZnO}$ nanoparticles with average particle size of $(40 \mathrm{~nm})$. Our study showed the enhanced antibacterial activity of ZnO nanoparticles chitosan (different MW) of against a gram-negative bacterium Escherichia coli DSMZ 498 and a gram-positive Micrococcus luteus ATCC 9341 in repeated experiments. The antibacterial activity of textile treated with $\mathrm{ZnO}$ nanoparticles chitosan increases with decreasing the molecular weight of chitosan.

\section{Introduction}

In the recent years, the environmental pollution and the population explosion have forced researchers to find new health-connected products for the human using. For textile industry, there are growing needs to develop finishes for textile materials which can offer improved protection to the user from UV radiation, bacteria, or fungi [1].

There is a great demand for antibacterial finishes on textile, since textile considered an ideal environment for bacterial growth. A huge number of chemicals are used in textile processes. But many of these chemicals are toxic to humans and do not easily degrade in the environment. The textile industry always looks for eco-friendly processes that replace toxic textile chemicals. These facts have facilitated the use of chitosan as a textile chemical. Chitosan, an important and commercially available biopolymer, has many chemical attributes to make it an interesting candidate for textile application. Chitosan has been found to be an interesting biopolymer for immobilization of desired biomolecules because of excellent film-forming ability, high permeability, and mechanical strength, nontoxicity, biocompatibility, easy availability, low cost, and containing reactive amino groups [2].

Chitosan is the deacetylated derivative of chitin (Figure 1 ), which is the second most abundant polysaccharide found on earth next to cellulose, it is obtained commercially from shrimp or crab shell chitin (a $\mathrm{N}$-acetylglucosamine polymer) by alkaline deacetylation in various grades $[3,4]$. It has been reported that chitosan gives considerable antibacterial activity against a broad spectrum with bacteria [5]. 


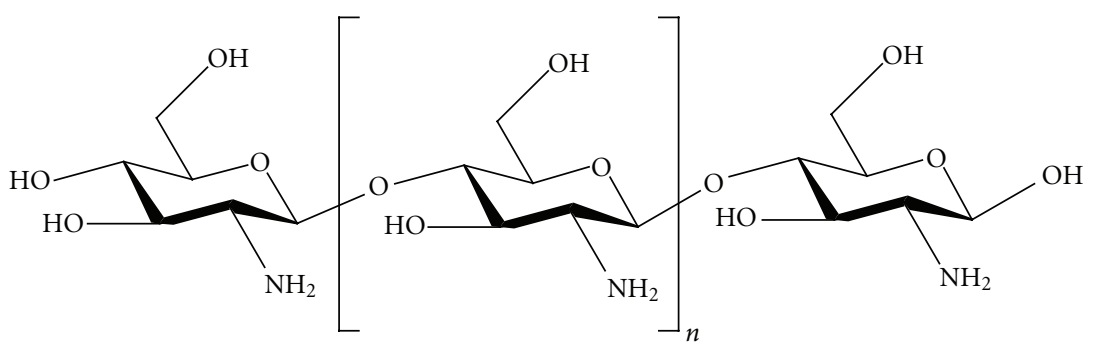

FIGURE 1: Chemical structure of chitosan.

However, the lack of strong chemical bonding with textile substrate became the major drawback for chitosan antibacterial application because of the problem in durability against repeated laundering [6].

As antibacterial agent, there are many studies that investigate the antibacterial action of $\mathrm{ZnO}$ nanoparticles. For example, some of the authors reported that $\mathrm{ZnO}$ particles have antibacterial activity against both Gram-positive and Gram-negative bacteria [7]. Yamamoto et al. reported that both the concentration and the surface area of the particles play an important part in the antibacterial activity evaluation, but the crystalline structure and the particle shape have lower effect. Yamamoto also reported that the antibacterial activity increased as the particle size decreased [8,9]. Adams et al., Brayner et al., and Jeng and Swanson reported that $\mathrm{ZnO}$ has a better effect on the microorganisms than other metal oxides such as $\mathrm{SiO}_{2}, \mathrm{MgO}, \mathrm{TiO}_{2}$, and $\mathrm{CaO}$ [10-12]. The observations reported by the researchers were explained by a number of mechanisms, these mechanisms include the production of active oxygen species due to the existence of the nanoparticles [13], damage of membrane cell wall because of the binding of the particles on the bacteria surface due to the electrostatic forces [14], penetration through the cell membrane [15], and interaction between the active oxygen species and the cell [16].

The present work was carried out with an objective to study the effect of $\mathrm{ZnO}$ nanoparticles sol-chitosan (different MW) composite on the antibacterial properties together with the physical and performance properties of treated fabrics. Figure 2 shows the proposed scheme for $\mathrm{ZnO}$ nanoparticle sol/chitosan composite.

\section{Experimental}

2.1. Materials and Chemicals. The coating process was carried out using $100 \%$ cotton $\left(250 \mathrm{~g} / \mathrm{m}^{2}\right)$ and $65 / 35 \%$ cotton/polyester $\left(162 \mathrm{~g} / \mathrm{m}^{2}\right)$ fabrics. Chitosan with average molecular weight of $1.36 \cdot 10^{5}, 2.7 \cdot 10^{5}$, and $3.0 \cdot 10^{5} \mathrm{Da}$ with a degree of deacetylation of $85 \%$ and with code name S85-60, 85-250, and 85-500, respectively (Heppe $\mathrm{GmbH}$. Germany); acetic acid, nonionic detergent (Marlipal) from Sasol AG, Germany. 2,3,5-triphenyltetrazolium chloride (TTC) (Merck); Standard I-nutrient broth medium (SI) and Standard I-nutrient agar (SI-agar) (Merk). Zinc acetate dihydrate $(\mathrm{ZnAc})$, lithium hydroxide monohydrate
(98\%), and 2-propanol were obtained from Merck, (3Glycidyloxypropyl) trimethoxysilane (GPTMS, 98\%) from ABCR. For catalysing the crosslinking reaction of epoxy group of the GPTMS 1-methylimidazole (97\%, Fluka) was used.

2.2. Microorganism. Escherichia coli (E. coli) DSMZ498 and Micrococcus luteus ATCC 9341 were incubated overnight at $37^{\circ} \mathrm{C}$ in nutrient broth. The culture obtained was diluted with autoclaved nutrient broth to obtain cell suspensions which was adjusted to a final working concentration of $1 \times$ $10^{5}$ colony forming units $(\mathrm{CFU})$ per $\mathrm{mL}$.

2.3. Preparation of a GPTMS Sol. $10 \mathrm{~mL}$ GPTMS are dissolved in $100 \mathrm{~mL}$ isopropanol before hydrolysation using $0.01 \mathrm{M}$ hydrochloric acid. The resulting sol is stirred for at least $3 \mathrm{~h}$ to form the basis sol (concentration of GPTMS sol $9,1$ vol. $\%)$.

2.4. Preparation of Zinc Oxide Nanoparticles. The preparation procedure employed has been described in [17]. A two neck round bottom distillation flask was used to suspend $2.8 \mathrm{~g}$ of $\left(\mathrm{ZnAc} \cdot 2 \mathrm{H}_{2} \mathrm{O}\right)$ in $100 \mathrm{~mL}$ of isopropanol by reflux heating for three hours. $0.75 \mathrm{~g}$ lithium hydroxide was dissolved in $100 \mathrm{~mL}$ isopropanol at room temperature by magnetic stirring. The $\mathrm{ZnAc}$ suspension was cooled to ${ }^{\circ} \mathrm{C}$ before the lithium hydroxide solution was added dropwise under vigorous stirring. The mixture was treated in an ultrasonic bath (SONOREX TK 52H) at room temperature for about $2 \mathrm{~h}$.

2.5. Characterization of $\mathrm{ZnO}$ Nanoparticles. The size of the $\mathrm{ZnO}$ nanoparticles was measured by dynamic light scattering (DLS), using Zetasizer, Nano-S, produced by Malvern.

\subsection{Preparation of Zinc Oxide Nanoparticles/Chitosan Com-} posite. $0.5 \%(\mathrm{w} / \mathrm{v})$ of chitosan was dissolved in $1 \%(\mathrm{v} / \mathrm{v})$ aqueous acetic acid solution by stirring for $2-3 \mathrm{~h}$. The finishing solutions were prepared: zinc oxide nanoparticle $(200 \mathrm{~mL} / 45 \mathrm{~nm})$ solution, GPTMS sol $(110 \mathrm{~mL})$, and solutions of $100 \mathrm{~mL} / 0.5 \%$ chitosan were mixed together and sonicated for $2 \mathrm{~h}$. The $\mathrm{pH}$ of the solution containing chitosan was adjusted to be 5.5 . To the finishing solution $50 \mu \mathrm{L}$ of nonionic detergent was added to improve the wettability. 1-methylimidazol $(0.5 \mathrm{~mL} / 10 \mathrm{~mL}$ GPTMS $)$ was added as 


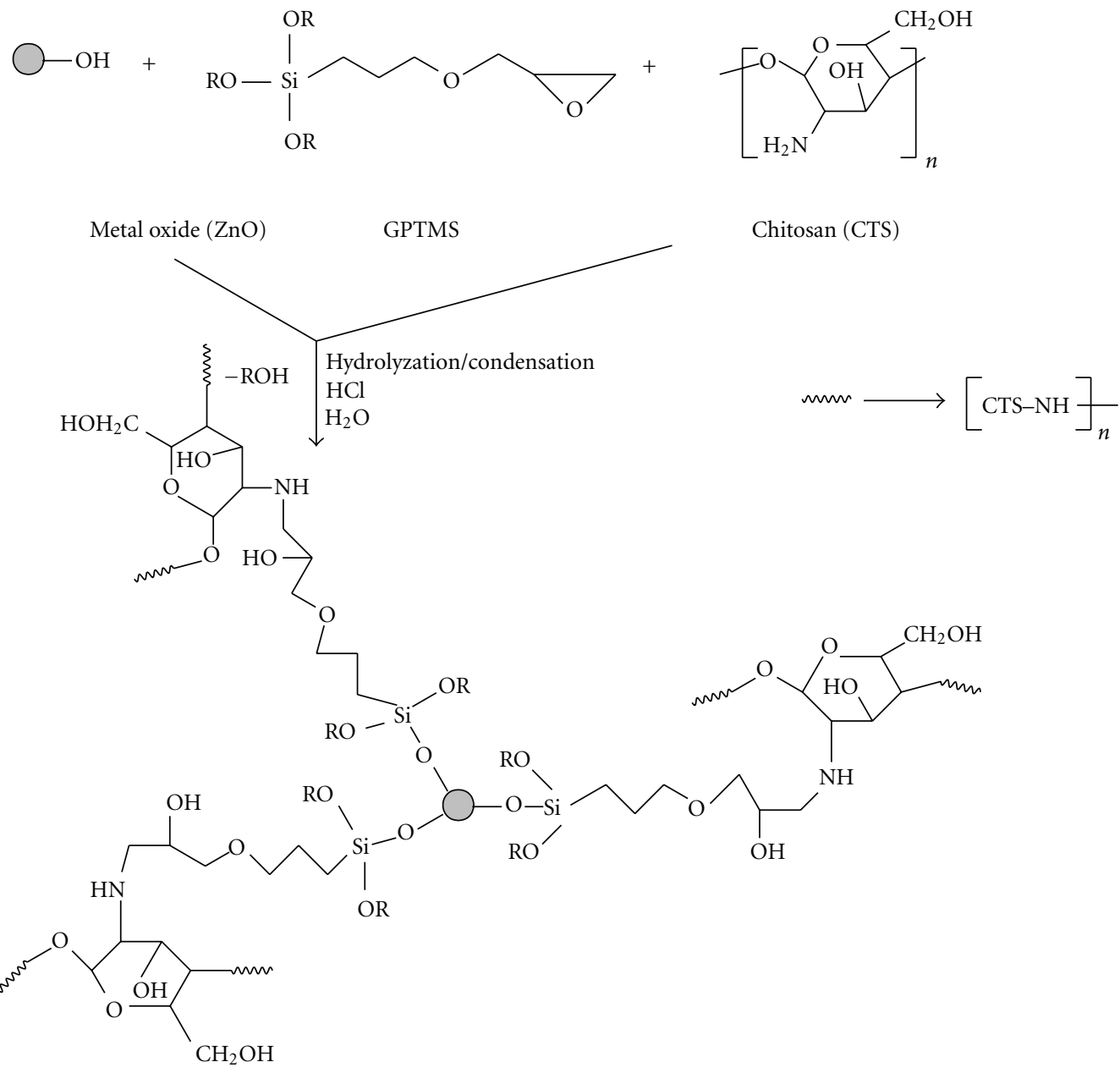

FIgure 2: Proposed scheme for the reaction of $\mathrm{ZnO}$ sol/chitosan composite.

a catalyst for the cross-linking reaction of the epoxy group of the GPTMS.

2.7. Coating Process. The fabrics were immersed in $\mathrm{ZnO}$ nanoparticles solution containing chitosan of different MW for 5-10 min at room temperature. Coatings were carried out using a lab padder (Werner Mathis AG, Switzerland) to a liquor uptake of $\sim 100 \%$. After padding samples were dried in a Labcoater LTE-S (Werner Mathis AG) at $130^{\circ} \mathrm{C}$ for 30 minutes. Washing was done using a laboratory washing machine at $40^{\circ} \mathrm{C}$.

2.8. Testing and Analysis of Zinc Oxide Nanoparticles/Chitosan Composite-Coated Fabrics. Different techniques were used to characterize the finished samples.

(i) Nitrogen content of the treated samples was determined according to Kjeldahl method [18].

(ii) Crease recovery angles (CRA) of the treated and untreated samples were measured according to DIN 53890 standard test method [19]. (iii) Tensile strength (TS) and elongation at break (E\%) were measured according to DIN standard test method [20].

(iv) The wettability test according to TEGAWA was applied [21].

(v) Stiffness of the fabric was tested using Shirley stiffness tester according to DIN 53362.

(vi) Changes in the degree of whiteness of the treated fabrics were evaluated with a Datacolor spectrophotometer 3880 (cocos Manual Version 2, 3). The degree of whiteness is given according to Berger (light source D65/10).

(vii) Antibacterial activity assays were carried out according to the zone of inhibition test, this is the testing method to evaluate the antibacterial activity of textiles treated with antibacterial finish $(\mathrm{ZnO}$ nanoparticles/chitosan composite) by the existence of halos, and this is applicable when antibacterial finishing chemicals can easily diffuse into plate agar culture medium. 


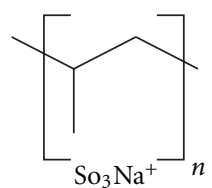

PESNa

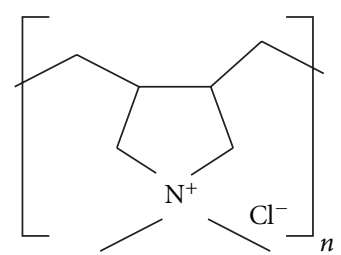

PDADMAC
FIGURE 3: Structure of cationic and anionic polyelectrolyte.

(viii) AATTC Test Method 100-2004 and tetrazolium/formazan test (TTC) which is described in details in [22].

(ix) Laundering was performed in a laboratory washing machine (Linitest, ATLAS) according to 6330:2000 for 5 washing cycles using standard ECE (European Colour fastness Establishment) detergent without fluorescent whitening agents (FWA's).

(x) Polyelectrolyte titration method: polyelectrolyte titration was carried out using polyelectrolyte titration system, particle charge detector (PCD $03 \mathrm{PH}$ ), was from Mütek Analytic GmbH, Herrsching, Germany. One gram climatized treated cottons were immersed in $100 \mathrm{~mL}$ acetate buffer solution $(\mathrm{pH}=4.7)$. To this solution $100 \mu \mathrm{L}$ Marlipal was added. The fabric samples were left under shaking for 2-3 h. Then the samples were washed several times with distilled water and dried at ambient conditions. $50 \mathrm{~mL}$ anionic polyelectrolyte $(0.001 \mathrm{~N}$ polyethlenesulfonic acid sodium salt; PES-Na) (Figure 1) and $100 \mu \mathrm{L}$ Marlipal were added with stirring, and the solutions with the fabrics were filtered out. $10 \mathrm{~mL}$ from the filtrate was titrated against cationic polyelectrolyte; polydiallyl-di-methyl-ammonium-chloride (PDADMAC $0.001 \mathrm{~N}$ ) (Figure 3 ). The volume consumed during the titration was called $\left(V_{1}\right)$. For calibration, $10 \mathrm{~mL}$ (PESNa) was titrated against (PDADMAC), and the volume determined was called $\left(V_{2}\right)$. The amount of titer consumption at the end point of titration can be used for the calculation of accessible charges according to the following equation:

$$
\begin{aligned}
& \text { MilliVolt } \cdot \text { equivalent }(\mathrm{mV} \cdot \text { eq. }) \\
& =\frac{\left[\left(V_{2}-V_{1}\right) \times 0.001\right]}{0.2},
\end{aligned}
$$

that is, $V_{1}=$ consumption of (PDADMAC) which is equivalent to the unreacted $(\mathrm{PESNa})(\mathrm{eq} / \mathrm{mL}), V_{2}=$ consumption of (PDADMAC) equivalent to $10 \mathrm{~mL}$ $(\mathrm{PESNa})(\mathrm{eq} / \mathrm{mL})$, for the correction of the volume which equivalent to the $1 \mathrm{~g}$ fabric sample, we multiply the $\left(V_{2}-V_{1}\right)$ by factor $5[4]$.

\section{Results and Discussion}

3.1. SEM Investigation. SEM investigations were carried out to examine changes in the topography after treatment process compared to the blank sample. The corresponding SEM micrographs are shown in Figure 4. As shown from the figure, after GPTMS-ZnO (30 nm) nanoparticles/chitosan composite the surface of the treated fabric became smoother compared with the untreated fabrics or fabric treated with only CTS due to the homogenious distribution of ZnO-CTS composite within the coating layer.

\subsection{Antibacterial Activity Measurement of $\mathrm{ZnO}$ Nanoparticles Solution Containing Chitosan of Different MW}

3.2.1. Qualitative Evaluation. In this study, the cellulosic fabrics were selected for the evaluation of the relative antibacterial activity of $\mathrm{ZnO}$ sol and $\mathrm{ZnO}$ sol/chitosan composite against a gram-negative bacterium E. coli, and a gram-positive Micrococcus lutues was studied qualitatively in aqueous LB broth by halo method (zone of inhibition). As shown in Figure 5, the antibacterial activity of finished fabric treated with $\mathrm{ZnO}$ sol/chitosan increased with chitosan $\mathrm{MW}$ decreased, this phenomenon was explained as the decrease of the MW of chitosan improves its solubility and improves the movement of polymer chains in the solution by decreasing the viscosity.

In Figure 5, the antibacterial activity against E. coli and $M$. luteus shows a clear zone of inhibition within and around the disc impregnated with (1) $\mathrm{ZnO}$ sol, (2) treated with $\mathrm{ZnO}$ sol/chitosan (higher MW) composite, (3) treated with $\mathrm{ZnO}$ sol/chitosan (medium MW), and (4) treated with $\mathrm{ZnO}$ sol/chitosan (lower MW).

3.2.2. Quantitative Evaluation. (The AATTC test method 100-2004) was first developed in 1961 by the AATCC Committee RA31, revised several times during the years, and reaffirmed in 1986 and 2004. The purpose of the AATCC Test Method is to "provide a quantitative procedure for the evaluation of the degree of antibacterial activity" of finishes on textile materials [23]. The method is based on inoculating test and control textile materials with chosen test organisms at $1-2 \times 10^{5}$ (colony-forming units) $\mathrm{CFU} / \mathrm{mL}$, usually in Nutrient broth. After incubation at $37^{\circ} \mathrm{C}$ for 18-24 hours, the microorganisms are eluted from the test samples by vigorous shaking in known amounts of solution, chosen to neutralize the antimicrobial effect. The number of microorganisms in the liquid is then determined via agar plating, and the percentage reduction by the treated samples is then calculated [23]. After that the number of bacteria was counted, and the reduction of bacteria, $R$, was calculated as follows:

$$
R \%=\frac{B-P}{B} \times 100
$$

where: $R=$ reduction in percentage, $B=\mathrm{CFU} /$ test sample in blank, $P=\mathrm{CFU} /$ test sample for treated samples.

The antibacterial activity of the coated fabrics was estimated for the E. coli and M. lutues according to the AATTC 100-2004 standard method. Figure 6 shows E. coli 


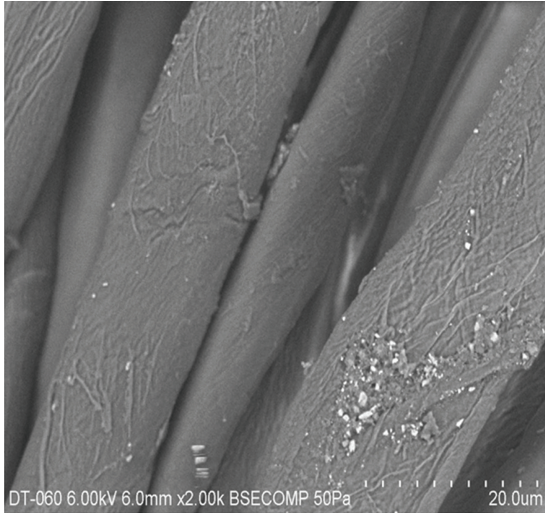

(a)

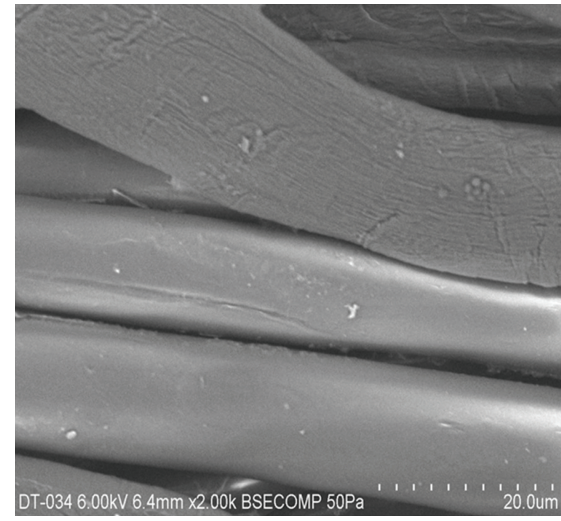

(b)

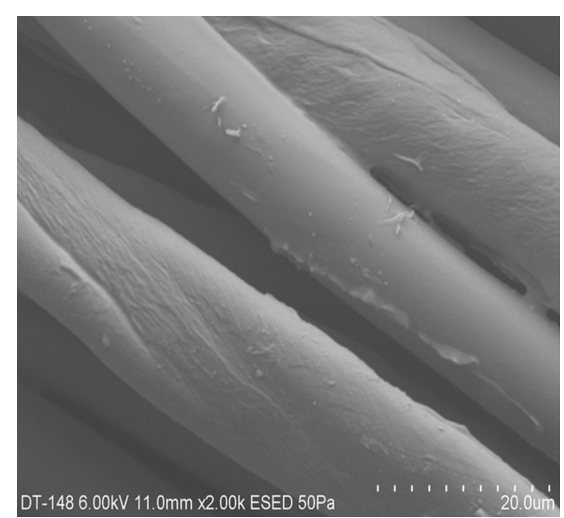

(c)

FIGURE 4: SEM photograph of the (a) untreated cotton/polester (65/35\%) fabric, (b) chitosan-treated fabric, and (c) ZnO nanoparticle sol/chitosan composite.

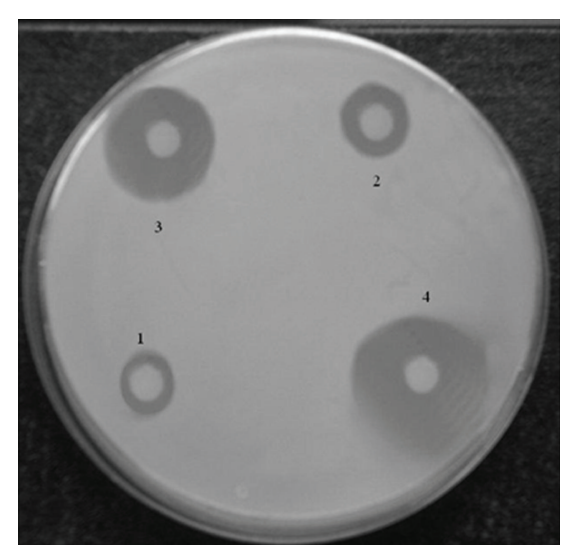

(a)

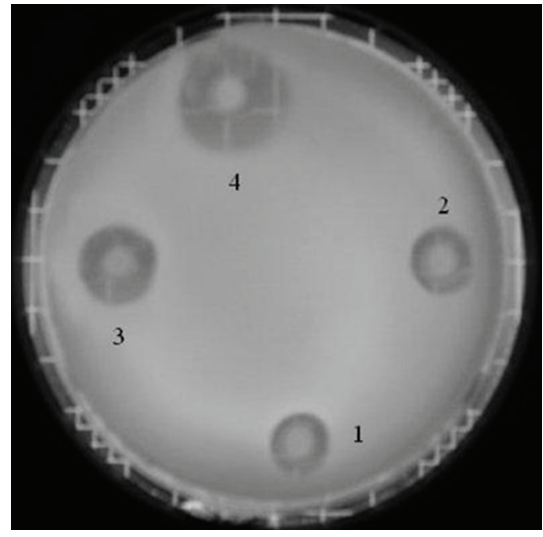

(b)

FIGURE 5: The qualitative disc diffusion test of cotton treated with $\mathrm{ZnO}$ sol/chitosan composite for the growth inhibition of (a) E. coli and (b) M. luteus. Both photographs show the clear zone of inhibition around the sample impregnated with ZnO nanoparticles compared with $\mathrm{ZnO}$ sol/chitosan (with different MW) composite.

and $M$. lutues bacterial growth with the time for GPTMS$\mathrm{ZnO}$ nanoparticles/chitosan (0.5\%) (low MW) compositetreated fabrics, (a) E. coli bacterial growth, and (b) M. Lutues bacterial growth.

From Figure 6, it was observed that, in case of both $E$. coli and $M$. lutues, there is nearly $100 \%$ reduction of the number of colonies after $3 \mathrm{~h}$ in case of cotton $100 \%$ treated fabrics against $E$. coli and $M$. lutues bacteria. In case of cotton $100 \%$ fabrics treated with GPTMS-CTS and GPTMS$\mathrm{ZnO}$ the complete reduction of the number of colonies was observed after $4 \mathrm{~h}$ and $5 \mathrm{~h}$, respectively.

From Figure 6 we can note that there is nearly 100\% reduction of the number of colonies after $3 \mathrm{~h}$ in case of cotton $100 \%$ treated fabric and cotton/polyester (65/35\%) treated fabric against $E$. coli and $M$. lutues bacteria.

It has been reported that chitosan confers considerable antibacterial activity against a broad spectrum of bacteria [24], and the interaction between positively charged chitosan and negatively charged bacterial cell wall leads to the leakage of intracellular constituents.
3.2.3. Quantitative and Qualitative Evaluation. The antibacterial activity of the treated fabric samples was evaluated against E. coli and Micrococcus luteus using the TTC test method. Details about this method are described by Fouda et al. [22]. This test serves as an indicating system for the determination of the viability of microorganisms, since that absorbance of formazane is directly proportional to the amount of living bacteria as shown in Figure 7.

As we observed from the formazan absorbance value in Figure 7, cotton/polyester fabric treated with $\mathrm{ZnO}$ nanoparticles sol/chitosan (low MW) composite has the lower absorbance value of formazan, indicating the higher antibacterial activity, compared to the formazan absorbance value of cotton/polyester treated with GPTMS-ZnO sol or cotton/polyester treated with GPTMS-CTS, we can see also that the antibacterial activity of cotton/polyester treated with GPTMS-CTS composite is more higher than that treated with GPTMS-ZnO sol. A presence of $\mathrm{ZnO}$ in the coating yields a reduction of more than $70 \%$ within three hours; a presence of CTS in the coating improves this value to more 


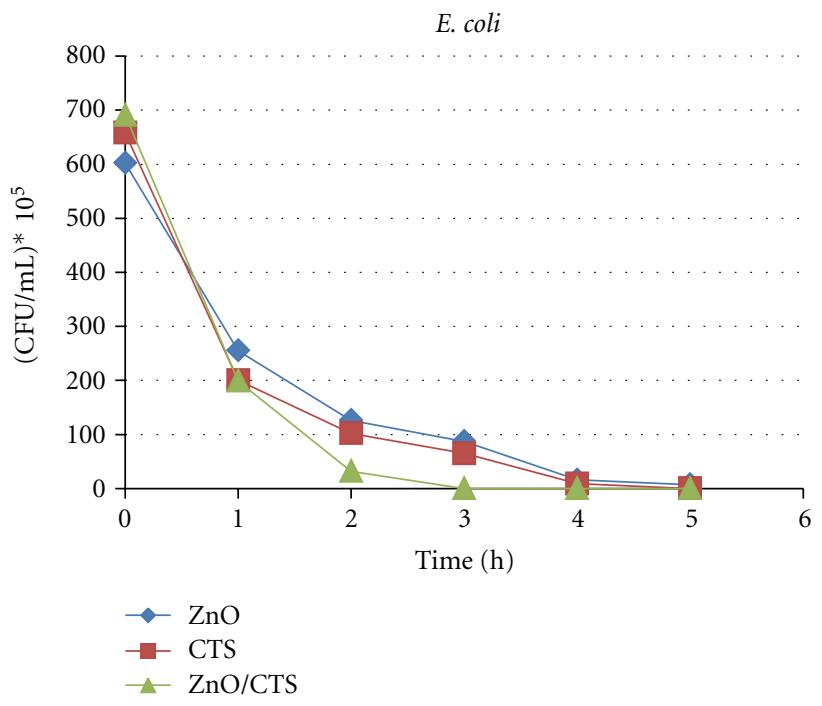

(a)

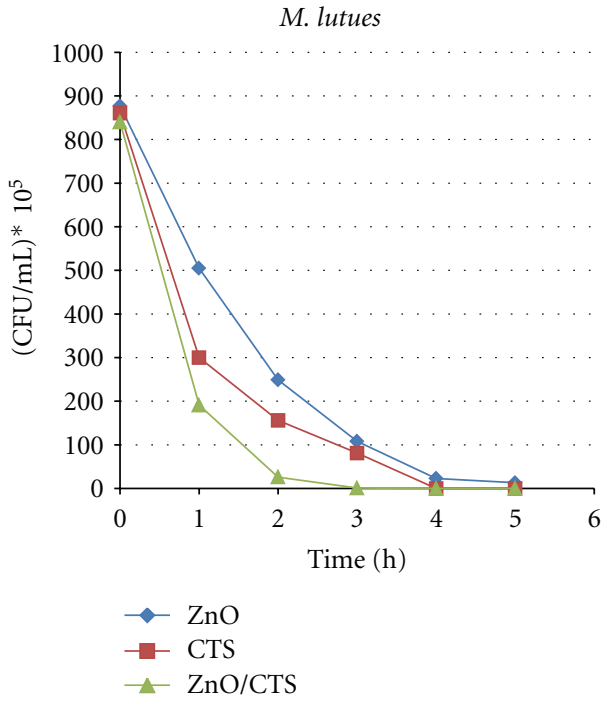

(b)

Figure 6: E. coli and M. lutues bacterial growth for ZnO nanoparticles sol/chitosan (low MW) composite-treated fabrics, (a) cotton 100\% treated fabric, and (b) cotton/polyester (65/35\%) treated fabric.

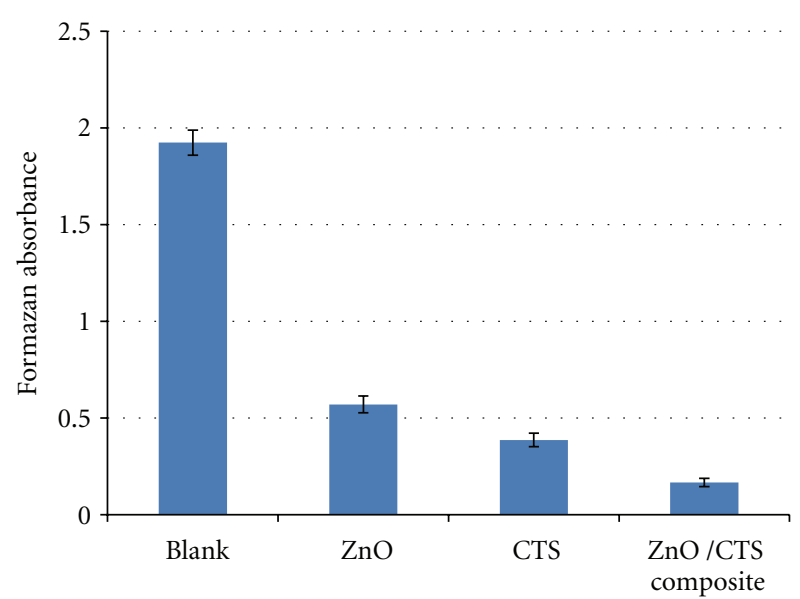

Figure 7: Absorbance of formazan for different cotton/polyester fabric treatment.

than $80 \%$, and the presence of $\mathrm{ZnO} / \mathrm{CTS}$ composite in the coating yields a reduction of approximately $92 \%$.

The antibacterial activity is in this order:

\section{GPTMS-ZnO-CTS composite > GPTMS-CTS com- posite > GPTMS-ZnO sol.}

\subsection{Characterization of the Amino Groups by Dropping} Colour. After the application of GPTMS-ZnO-CTS composite to the textile surface using the pad-dry-cure method, ninhydrin test as colouring test was done to determine the present degree of the $-\mathrm{NH}_{2}$ group of the Chitosan molecule on textile surface, since $-\mathrm{NH}_{2}$ group serves as basis for the test of Chitosan. This test is used mainly in order to discover the immobilized amino groups which are at the surface of

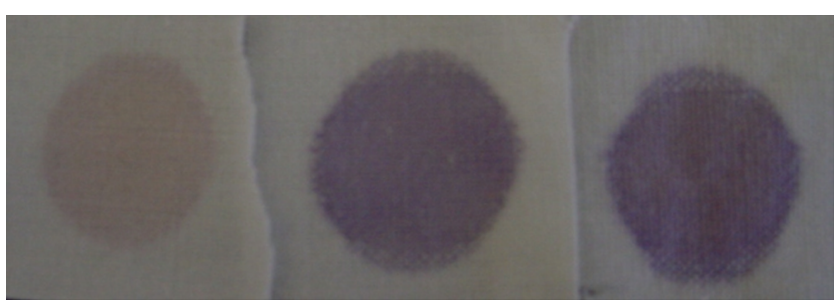

(a)

(b)

(c)

FIGURE 8: Dropping test for the identification of amino groups immobilized on treated cotton surface. (a) Cotton blank, (b) cotton treated with $\mathrm{ZnO}$ sol/chitosan composite, and (c) cotton treated with $\mathrm{ZnO}$ sol/chitosan (low MW) composite after washing.

finished fabrics which is considered most important factor for the antibacterial activity of chitosan.

Figure 8 is a dropping test for the identification of immobilized amino groups on treated cotton surface before and after washing. The figure shows that this test was positive for all finished chitosan-containing fabrics since the brownish colour of ninhydrin converts to violet as a result of the reaction with the chitosan amino groups (ninhydrin reacts with the free amino group of chitosan and develops a violet colour). The respective blank test showed no effect as shown.

\subsection{Polyelectrolyte Titration and Nitrogen Content of the} Treated Fabrics. Polyelectrolyte titration was carried out in order to determine the amount of charged amino groups immobilized on cotton and cotton/polyester surfaces. Polyelectrolyte titration measurements on the treated fabrics may be used to assess the availability of ionic charges on the fabrics which give information on the (statistical) sites 
TABLE 1: Polyelectrolyte titration and nitrogen content results.

\begin{tabular}{|c|c|c|}
\hline Treated cotton with & $\begin{array}{l}\text { Amount of nitrogen } \\
\text { (mmol/g fibre) }\end{array}$ & $\begin{array}{c}\text { Amount of cationic charges } \\
\text { (meq/g fibre) }\end{array}$ \\
\hline $0.5 \%$ chitosan (lower MW) & 0.32 & 0.040 \\
\hline $0.5 \%$ chitosan (lower MW)/GPTMS & 0.53 & 0.057 \\
\hline GPTMS-ZnO $(10 \%, 30 \mathrm{~nm})$ & - & 0.032 \\
\hline GPTMS-ZnO $(10 \%, 30 \mathrm{~nm}) / 0.5 \%$ chitosan composite & 0.55 & 0.065 \\
\hline
\end{tabular}

TABLE 2: Effect of ZnO sol—chitosan on some performance properties of cotton and cotton blend fabric samples.

\begin{tabular}{|c|c|c|c|c|c|c|c|}
\hline Substrate & & $\begin{array}{c}\text { Tensile } \\
\text { strength } \\
(\text { daN) }\end{array}$ & $\begin{array}{c}\text { Elongation } \\
(\%)\end{array}$ & $\begin{array}{c}\text { Air } \\
\text { permeability } \\
\left(1 / \mathrm{dm}^{2} \cdot \mathrm{min} .\right)\end{array}$ & $\begin{array}{c}\text { Degree of } \\
\text { whiteness } \\
\text { (Berger) }\end{array}$ & $\begin{array}{l}\text { Bending } \\
\text { Stiffness } \\
\left.(\mathrm{cN} \mathrm{cm})^{2}\right)\end{array}$ & $\begin{array}{c}\text { CRA } \\
(\mathrm{W}+\mathrm{F})^{\circ}\end{array}$ \\
\hline \multirow{2}{*}{ Untreated } & Cotton & $102.1 \pm 0.75$ & $21.9 \pm 1.06$ & 250.5 & 66.0 & $12.19 \pm .025$ & $143^{\circ}$ \\
\hline & $\mathrm{CO} / \mathrm{PET}$ & $87.4 \pm 1.02$ & $31.7 \pm 1.04$ & 334.0 & 70.9 & $3.23 \pm .029$ & $175^{\circ}$ \\
\hline \multirow{2}{*}{ Treated with $\mathrm{ZnO}$ in GPTMS-sol (10\%) } & Cotton & $96.5 \pm 1.25$ & $22.9 \pm 1.15$ & 258.8 & 56.1 & $13.64 \pm .014$ & $150^{\circ}$ \\
\hline & $\mathrm{CO} / \mathrm{PET}$ & $86.6 \pm 1.35$ & $33.3 \pm 1.45$ & 350.7 & 68.3 & $5.47 \pm .017$ & $181^{\circ}$ \\
\hline \multirow{2}{*}{ Treated with chitosan/GPTMS } & Cotton & $107.7 \pm 1.47$ & $23.8 \pm 0.95$ & 245.3 & 53.7 & $15.88 \pm .014$ & $180^{\circ}$ \\
\hline & $\mathrm{CO} / \mathrm{PET}$ & $94.2 \pm 1.025$ & $33.7 \pm 1.02$ & 328.4 & 64.9 & $7.38 \pm .022$ & $196^{\circ}$ \\
\hline \multirow{2}{*}{ Treated with chitosan of low MW } & Cotton & $104.8 \pm 1.04$ & $21.9 \pm 1.14$ & 247.0 & 54.8 & $15.12 \pm .024$ & $178^{\circ}$ \\
\hline & $\mathrm{CO} / \mathrm{PET}$ & $91.3 \pm 1.14$ & $31.9 \pm 0.85$ & 330.5 & 65.6 & $6.65 \pm .041$ & $187^{\circ}$ \\
\hline \multirow{2}{*}{ Treated with $\mathrm{ZnO}$ sol/chitosan } & Cotton & $107.2 \pm 1.03$ & $23.5 \pm 1.12$ & 243.2 & 53.1 & $16.93 \pm .017$ & $181^{\circ}$ \\
\hline & $\mathrm{CO} / \mathrm{PET}$ & $92.7 \pm 0.98$ & $33.0 \pm 1.07$ & 326.1 & 64.3 & $8.81 \pm .026$ & $197^{\circ}$ \\
\hline \multirow{2}{*}{ Treated with GPTMS } & Cotton & $99.8 \pm 1.01$ & $21.5 \pm 1.22$ & 257.6 & 56.9 & $13.11 \pm .028$ & $151^{\circ}$ \\
\hline & $\mathrm{CO} / \mathrm{PET}$ & $86.3 \pm 1.41$ & $31.4 \pm 1.31$ & 350.0 & 69.4 & $4.83 \pm .025$ & $181^{\circ}$ \\
\hline
\end{tabular}

of crosslinker and on possible chain segment mobility of biopolymer on fibre [22].

As it was observed from Table 1 that the amount of nitrogen and the amount of cationic charges of only chitosan treated fabric are weak compared to fabric treated with $0.5 \%$ chitosan (lower MW)/GPTMS which were explained by effect of GPTMS which works as crosslinking agent for the chitosan into the cotton fabric surface. Also the amount of cationic charges increased in case of cotton treated with GPTMSZnO $(10 \%, 30 \mathrm{~nm}) / 0.5 \%$ chitosan composite due to the presence of cationic charge from both chitosan as well as $\mathrm{ZnO}$ nanoparticles surface.

In case of nitrogen content measurements all the amount of nitrogen can be detected, but in case of polyelectrolyte titration the amount of cationic charges which was detected is lower than the expected value. This is because of that not all nitrogen charges are available for the polyelectrolyte titration, since the cationic charges which were detected are only the charges on the surface.

The mechanical data of the treated and untreated samples and the influence of the $\mathrm{ZnO}$ sol/chitosan composite treatment for the degree of whiteness, the air permeability, stiffness, tensile strength, and crease recovery angle were investigated and the corresponding data are given in Table 2.

(i) As it was expected, the tensile strength of fabric samples treated with chitosan, chitosan/GPTMS, and $\mathrm{ZnO}$ sol/chitosan slightly increased. The increase may be attributed to the penetration of chitosan molecule which made some sort of sizing to the treated fabrics and enhance the tensile strength.

(ii) The CRA enhancement of the chitosan finished fabrics suggests that chitosan undergoes cross-linking with GPTMS on the fabric to form network hybrid matrix.

(iii) Also the whiteness of the fabrics is slightly decreased, but in a tolerable degree.

(iv) Air permeability is an important factor in the performance of textile materials used to give an indication to the breathability of the coated fabrics, and within the investigation summarized in Table 2 it can be seen that there is no reduction of the air permeability values in case of fabrics treated with GPTMS and $\mathrm{ZnO}$ in GPTMS-sol but at least slight increased, but in case of fabrics treated with chitosan a slight decrease could be due to closing of open interstices caused by mechanical deposition of the finish [25].

(v) Bending stiffness of the fabrics increasing could be due to the higher uptake of the inorganic-organic hybrids polymers containing chitosan molecules on cellulosic fabric surface which made the structure more rigid.

\section{Conclusion}

The present work is a complete part of previously work done on studying of the antibacterial activity of $\mathrm{ZnO}$ 
nanoparticle sol. In order to investigate the effect of the MW on the antimicrobial activity of chitosan, cellulosic fabrics were treated with three chitosans with different MWs and similar DDA. The antimicrobial activity of the treated fabrics was tested in terms of the reduction rate using two strains of bacteria. In addition, the performance properties of the treated fabrics were evaluated. From the results we found that $\mathrm{ZnO}$ sol/chitosan (low MW) has better antibacterial activity since the decrease of molecular weight of chitosan increases the antibacterial activity, and this phenomenon was explained as the decrease of chitosan molecular weight in the composite improves the movement of the chains in the solution by decreasing the viscosity.

\section{Acknowledgment}

Very special thanks are due to the Egyptian Missions Department for giving A. Farouk the opportunity and the financial support to pursue her Ph.D. degree in Germany. Further financial support by the Ministerium für Innovation, Wissenschaft, Forschung und Technologie des Landes Nordrhein-Westfalen (Department of Innovation, Science, Research and Technology of the state of NordrheinWestfalen) is thankfully acknowledged.

\section{References}

[1] V. R. G. Dev, J. Venugopal, S. Sudha, G. Deepika, and S. Ramakrishna, "Dyeing and antimicrobial characteristics of chitosan treated wool fabrics with henna dye," Carbohydrate Polymers, vol. 75, no. 4, pp. 646-650, 2009.

[2] R. Khan, A. Kaushik, P. R. Solanki, A. A. Ansari, M. K. Pandey, and B. D. Malhotra, "Zinc oxide nanoparticles-chitosan composite film for cholesterol biosensor," Analytica Chimica Acta, vol. 616, no. 2, pp. 207-213, 2008.

[3] D. Knittel and E. Schollmeyer, "Chitosan und seine derivate für die textilveredlung," Melliand Textil Berichte, vol. 1, pp. 5861, 2002.

[4] M. M. G. Fouda, R. Wittke, D. Knittel, and E. Schollmeyer, "Use of chitosan/polyamine biopolymers based cotton as a model system to prepare antimicrobial wound dressing," International Journal of Diabetes Mellitus, vol. 1, no. 1, pp. 61-64, 2009.

[5] C. H. Su, C. S. Sun, S. W. Juan, C. H. Hu, W. T. Ke, and M. T. Sheu, "Fungal mycelia as the source of chitin and polysaccharides and their applications as skin substitutes," Biomaterials, vol. 18, no. 17, pp. 1169-1174, 1997.

[6] W. Ye, J. H. Xin, P. Li, K. L. D. Lee, and T. L. Kwong, "Durable antibacterial finish on cotton fabric by using chitosan-based polymeric core-shell particles," Journal of Applied Polymer Science, vol. 102, no. 2, pp. 1787-1793, 2006.

[7] J. Sawai, "Quantitative evaluation of antibacterial activities of metallic oxide powders $(\mathrm{ZnO}, \mathrm{MgO}$ and $\mathrm{CaO})$ by conductimetric assay," Journal of Microbiological Methods, vol. 54, no. 2, pp. 177-182, 2003.

[8] O. Yamamoto, M. Hotta, J. Sawai, T. Sasamoto, and H. Kojima, "Influence of powder characteristic of $\mathrm{ZnO}$ on antibacterial activity_effect of specific surface area," Journal of the Ceramic Society of Japan, vol. 106, no. 10, pp. 1007-1011, 1998.
[9] O. Yamamoto, "Influence of particle size on the antibacterial activity of zinc oxide," International Journal of Inorganic Materials, vol. 3, no. 7, pp. 643-646, 2001.

[10] L. K. Adams, D. Y. Lyon, and P. J. J. Alvarez, "Comparative ecotoxicity of nanoscale $\mathrm{TiO}_{2}, \mathrm{SiO}_{2}$, and $\mathrm{ZnO}$ water suspensions," Water Research, vol. 40, no. 19, pp. 3527-3532, 2006.

[11] R. Brayner, R. Ferrari-Iliou, N. Brivois, S. Djediat, M. F. Benedetti, and F. Fiévet, "Toxicological impact studies based on Escherichia coli bacteria in ultrafine $\mathrm{ZnO}$ nanoparticles colloidal medium," Nano Letters, vol. 6, no. 4, pp. 866-870, 2006.

[12] H. A. Jeng and J. Swanson, "Toxicity of metal oxide nanoparticles in mammalian cells," Journal of Environmental Science and Health Part A, vol. 41, no. 12, pp. 2699-2711, 2006.

[13] S. Makhluf, R. Dror, Y. Nitzan, Y. Abramovich, R. Jelinek, and A. Gedanken, "Microwave-assisted synthesis of nanocrystalline $\mathrm{MgO}$ and its use as a bacteriocide," Advanced Functional Materials, vol. 15, no. 10, pp. 1708-1715, 2005.

[14] P. K. Stoimenov, R. L. Klinger, G. L. Marchin, and K. J. Klabunde, "Metal oxide nanoparticles as bactericidal agents," Langmuir, vol. 18, no. 17, pp. 6679-6686, 2002.

[15] H. Xu, H. Wang, Y. Zhang et al., "Hydrothermal synthesis of zinc oxide powders with controllable morphology," Ceramics International, vol. 30, no. 1, pp. 93-97, 2004.

[16] L. Zhang, Y. Jiang, Y. Ding, M. Povey, and D. York, "Investigation into the antibacterial behaviour of suspensions of $\mathrm{ZnO}$ nanoparticles ( $\mathrm{ZnO}$ nanofluids)," Journal of Nanoparticle Research, vol. 9, no. 3, pp. 479-489, 2010.

[17] A. Farouk, T. Textor, E. Schollmeyer, A. Tarbuk, and A. M. Grancacic, "Sol-gel-derived inorganic-organic hybrid polymers filled with zno nanoparticles as an ultraviolet protection finish for textiles," Autex Research Journal, vol. 10, no. 3, pp. 58-63, 2010.

[18] A. I. Vogel, Text-Book of Quantitative Inorganic Analysis (Elemental Practical Inorganic Chemistry) Part 3, Quantitative Inorganic Analysis, Longman, 1975.

[19] German DIN Book, "Methods of Analysis," 53890, January 1972.

[20] German DIN Book, "Methods of Analysis," 255-262, 1979.

[21] S. Breichter, P. Wurster, and G. Schmidt, Melliand Text Berichte, vol. 8, pp. 581-583, 1987.

[22] M. Fouda, D. Knittel, R. Zimehl, C. Hipler, and E. Schollmeyer, "Functionalization of fibre surfaces by thin layers of chitosan and the antimicrobial activity," Advances in Chitin Science, vol. 8, p. 418, 2005.

[23] AATCC Committee, Antibacterial Finishes on Textile Materials: Assessment of 2004, AATCC, 2004.

[24] C. H. Su, C. S. Sun, S. W. Juan, C. H. Hu, W. T. Ke, and M. T. Sheu, "Fungal mycelia as the source of chitin and polysaccharides and their applications as skin substitutes," Biomaterials, vol. 18, no. 17, pp. 1169-1174, 1997.

[25] A. Karolia and S. Mendapara, "Imparting antimicrobial and fragrance finish on cotton using chitosan with silicon softener," Indian Journal of Fibre and Textile Research, vol. 32, no. 1, pp. 99-104, 2007. 


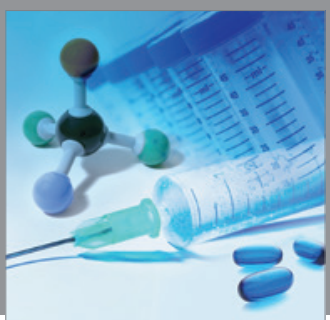

International Journal of

Medicinal Chemistry

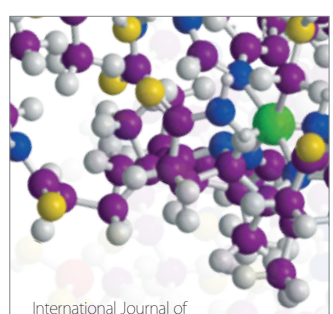

Carbohydrate Chemistry

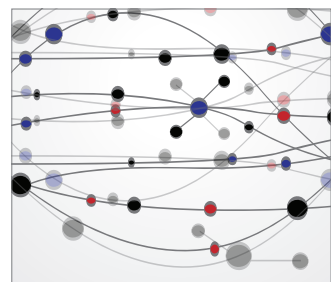

The Scientific World Journal
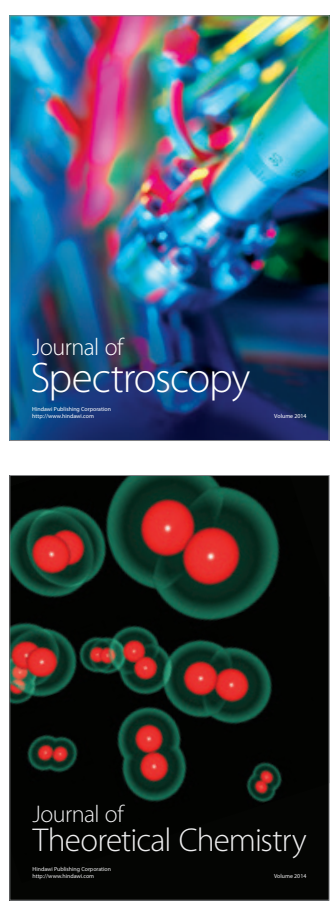
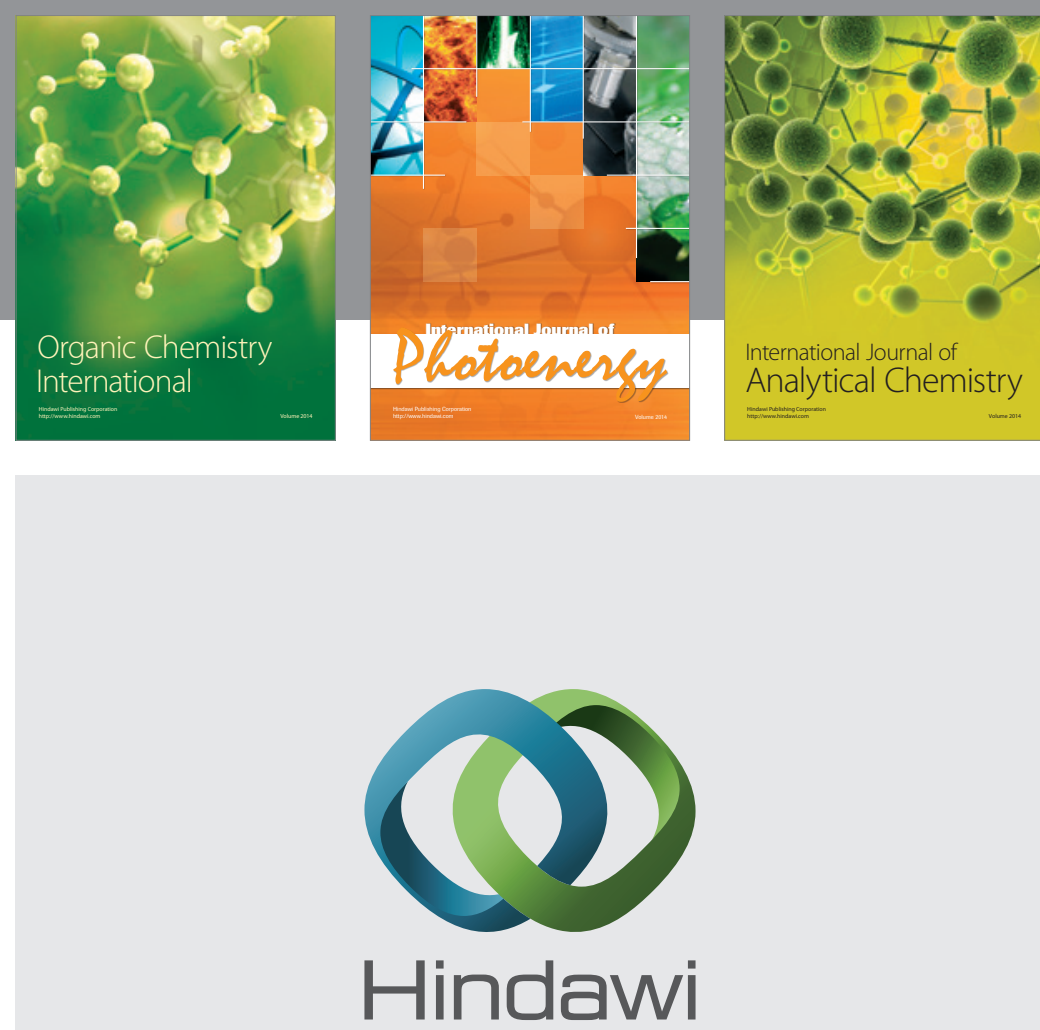

Submit your manuscripts at

http://www.hindawi.com
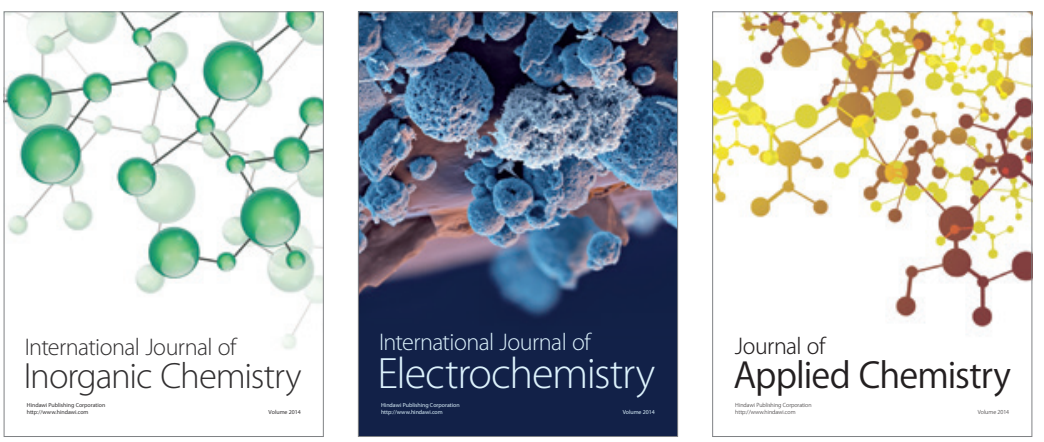

Journal of

Applied Chemistry
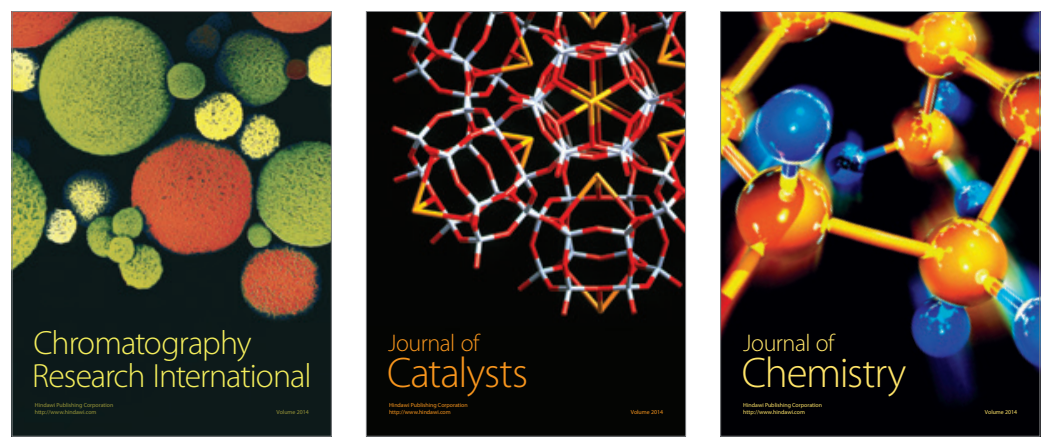
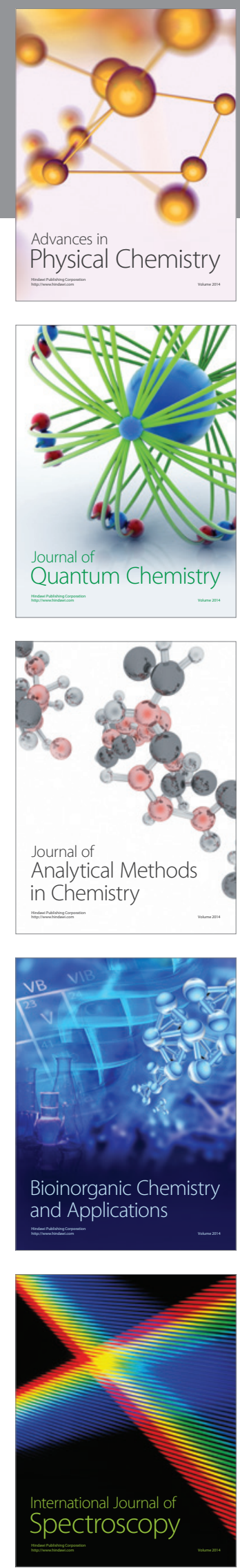